\title{
Magnitude, Symptom Presentation and Correlates of Psychological Distress Among People with Epilepsy in Southern Ethiopia: A Cross-Sectional Study
}

This article was published in the following Dove Press journal:

Neuropsychiatric Disease and Treatment

\author{
Birhanie Mekuriaw (D) \\ Bahru Mantefardo ${ }^{2}$ \\ Alemayehu Molla (1) \\ Getasew Berhanu ${ }^{3}$ \\ Tsegaye Mehare (D) ${ }^{4}$ \\ Zelalem Belayneh (D) \\ 'Department of Psychiatry, College of \\ Health and Medical Science, Dilla \\ University, Dilla, Ethiopia; ${ }^{2}$ Department \\ of Internal Medicine, College of Health \\ and Medical Science, Dilla University, \\ Dilla, Ethiopia; ${ }^{3}$ Department of Statistics, \\ College of Natural and Computational \\ Science, Dilla University, Dilla, Ethiopia \\ ${ }^{4}$ Biomedical Department, College of \\ Health and Medical Science, Dilla \\ University, Dilla, Ethiopia
}

Background: Psychological distress is a common co-morbid condition among people with epilepsy. Untreated comorbid psychosocial problems are associated with increased morbidity and health-care costs, and negatively affects treatment outcome of people with epilepsy. Therefore, the aim of this study was to describe the prevalence of psychological distress and to identify its associated factors among people with epilepsy attending outpatient treatment in Gedeo zone public hospitals, Southern Ethiopia.

Patients and Methods: This was an institution-based cross-sectional study conducted at Gedeo zone public hospitals from July 1st to October 1st, 2019. Self-reporting questionnaire was used to screen individuals with epilepsy for the presence of co-morbid psychological distress. A face to face interview was conducted among 321 anti-epileptic medication followers. The collected data were entered into Epi-Data version 3.1 and then exported to SPSS version 20 for further analysis. Binary logistic regression was computed to identify factors associated with psychological distress. Statistically, significant association was set at $p$-values of $<0.05$ in the final model with a corresponding $95 \%$ confidence interval.

Results: The prevalence of psychological distress was found to be $38.3 \%$ with $95 \% \mathrm{CI}$ $(34.1,42.7)$ among people with epilepsy attending outpatient follow-up in Gedeo zone public hospitals. Being female [OR=1.57 (95\% CI: 1.01-4.80)], uncontrolled seizures [OR=1.96 (95\% CI: 1.21-3.18)], and longer duration of illness [OR=3.16 (95\% CI: $1.75-5.73)]$ were variables found to have statistically significant association with psychological distress.

Conclusion: The findings of this study revealed that more than one-third of people with epilepsy screened positive for psychological distress. Therefore, this demonstrates a need to design and implement programs focusing on the prevention, early screening, and providing appropriate interventions for psychological distress among people with epilepsy.

Keywords: psychological distress, mental distress, epilepsy, seizure, common mental disorder, comorbidity, Ethiopia

\section{Introduction}

Epilepsy is a group of chronic neurological disorders characterized by repeated seizure attacks, which are the result of abnormal, excessive, or hypersynchronous neuronal activity in the brain. ${ }^{1,2}$ It is considered the most common neurological disorder in the world, affecting about 50 million people in all age groups. ${ }^{3}$ Even though it is an under-recognized and often untreated problem, epilepsy is
Correspondence: Birhanie Mekuriaw Email birhanie20I3@gmail.com
Neuropsychiatric Disease and Treatment 2020:16 2|43-2|5| 
considered a public health concern. Its lifetime prevalence is reported to be 5.8 per 1000 and 12.7 per 1000 in developed nations and rural areas of developing countries, respectively. ${ }^{4,5}$ Large proportions or nearly $80 \%$ of people with epilepsy live in low and middle income countries, and nearly half of the patients do not get appropriate treatments which in turn can expose them to further biological or psychological comorbidities. ${ }^{6,7}$

In Ethiopia, the epidemiological finding showed that approximately 400 thousand people are living with active epilepsy and nearly 3000 people have died due to epilepsy. ${ }^{8}$ Despite many underlined and precipitating conditions that have been investigated to lead to epilepsy, the exact cause of epilepsy is still not known for about half of people with epilepsy globally., ${ }^{7,8}$ Thus, the diagnosis of epileptic seizures and ascertainment of the cause are difficult tasks, especially in low-income countries where cultural constraints are obstacles to the recognition and acceptance of the disease, and where people believe that seizure attacks are caused by supernatural forces and culturally attributed norms. ${ }^{9}$ The recurrence of seizures and their psychological consequences make epilepsy a burdensome neurological disorder. ${ }^{5}$

Mental health and psychosocial problems are common comorbid conditions among people with epilepsy. ${ }^{10,11}$ Psychological distress (standing for a vast array of symptoms of depression, anxiety, or unexplained somatoform syndromes) ${ }^{6}$ is a major public health concern and approximately 500 million people are suffering from it. Psychological distress accounts for $14-17 \%$ of the total burden of diseases and severe psychological distress accounts for 25.3 and $33.5 \%$ of all years lived with a disability in low- and middle-income countries, respectively. ${ }^{12}$ Its figure becomes much higher among people with epilepsy as compared to the general population. This might be due to the poor perception of illness, stigma and discrimination, pill burden, medication side effects, fear of seizure attack, and difficulty of coping with the sick role. Not only do seizures cause psychological distress, but also anti-epileptic drugs (AEDs) can play a role in the genesis of the symptoms. ${ }^{7,13}$ On the other hand, some psychotropic medications (drugs for psychiatric treatment) can also lower the seizure threshold and provoke epileptic seizure attacks. ${ }^{11,14}$ The presence of comorbid psychological distress negatively affects the treatment outcome of people with epilepsy, because it can lead to substance use, poor treatment adherence, lower productivity, increased stigma and discrimination, and social re-engagement of people with epilepsy. ${ }^{15,16}$

Despite such multimodal consequences and unpredicted magnitude of psychological distress among people with epilepsy, it is not well researched in Ethiopia. Therefore, the aim of this study was to measure the magnitude and associated factors of psychological distress among people with epilepsy in southern Ethiopia.

\section{Patients and Methods Study Design and Period}

This was an institutional-based cross-sectional study conducted from July 1st to October 1st, 2019.

\section{Study Setup and Participants}

This study was conducted at Gedeo zone public hospitals among people with epilepsy having outpatient follow-up. Dilla is the zonal city of Gedeo people (one of the thirteen zones of Southern Nation Nationalities and Peoples of Region) located at 359 kilometers to the southeast of Addis Ababa (the capital city of Ethiopia). The zone has seven woredas (districts found in the zone) and two city administrations. Based on the 2007 census conducted by the central statistical agency (CSA), Gedeo zone has a total population of 847,434 $(424,742=$ male and $422,692=$ female $) .{ }^{17}$ The zone has three governmental hospitals and one teaching and referral hospital (Dilla University Referral Hospital). A mental and neurological health service was provided in all hospitals.

\section{Sample Size and Procedures}

First, a census was conducted among two public hospitals (Dilla and Gedeb) regarding the number of people with epilepsy attending the outpatient department using the Health Management Information System (HMIS) from the registration book. A total of 414 people attending antiepileptic treatment were identified from the registration book. Then, patients with age of less than 16 years, medically ill individuals, those with unconfirmed epileptic diagnosis and individuals who missed their clinical appointment for more than six months were excluded. Accordingly, a total of 321 patients with epilepsy were found to be eligible to participate in this study and were invited to take part in the interview in a confidential manner. 


\section{Data Collection Procedures}

The data were collected using a pre-tested intervieweradministered questionnaire. The questionnaire was first prepared in the English language. Then, two experts translated to Gedeufa and another two changed it to the Amharic language independently. Back translation was also done to English by other language experts (two for each language). When there were disagreements between translators, we invited a third neutral translator to form a final and coherent version of the questionnaire. Before the data collection, a pretest was done among 17 people with epileptic seizures (5\% of the sample size) at Hawassa referral hospital located at 88 kilometers from the study area. Based on the pretest results, minor modification was done on the contents of the questionnaire and the expression of some questions was rephrased to make them easily understandable and culturally appropriate.

Seven Bachelor of Science (BSc) psychiatric nurses and two Master of Science (MSc) level mental health professionals participated in the data collection after attending two days of training. Data collectors and supervisors were assigned to each hospital until the proposed numbers of participants were addressed. The principal investigators and supervisors checked the collected data for completeness and consistency.

\section{Measurements}

The questionnaire had different sections including sociodemographic factors, clinical related characteristics, substance use and psychosocial related variables, and the outcome variable (Supplementary Material).

The outcome variable (psychological distress) was assessed using Self-Reporting Questionnaire (SRQ-20) which has been developed by the World Health Organization (WHO) to screen mental distress in primary health-care settings and communities of low-income countries. ${ }^{18}$ SRQ-20 is a widely used and validated instrument for epidemiological studies in clinical and community settings. ${ }^{19,20}$ SRQ-20 has twenty "Yes" or "No" questions that can be scored as 1 for "Yes" responses and 0 for "No" answers. SRQ-20 questions can identify symptoms of depression, anxiety, and somatoform disorders. By summing up such scores together, SRQ has a total sum score ranging from 0 to 20. We used the Ethiopian version of SRQ-20 which has been used to measure psychological distress. ${ }^{19}$ In this study, psychological distress was considered for participants with a total SRQ sum score of $\geq 7$ based on the questionnaire psychometric property and previous experience in various population studies. ${ }^{20-23}$ The SRQ-20 items showed good internal consistency in this study as evidenced by a Cronbach alpha of 0.89 .

The level of social support was also assessed using the Oslo-3 item Social Support Scale (OSSS-3). ${ }^{24}$ The tool has three questions which collectively assess the level of interest, concerns that people show, and the accessibility of practical help from neighbors during great personal problems. OSSS-3 has a total sum score ranging from 3 to 14. A higher sum score corresponds to a stronger level of social support of individuals. The sum score of OSSS-3 was categorized as poor social support (3-8), moderate social support (9-11), and strong social support level (12-14). In addition, the scale was widely used in the Ethiopian population to measure the level of social support in clinical and community settings. ${ }^{25,26}$

\section{Operational Definitions Substance Use}

In this study, substance use is defined as "current use" of psychoactive substances (khat, alcohol, tobacco).

\section{Current Use}

This refers to the use of psychoactive substances (khat, alcohol, or cigarette) in any amount within the last three months.

\section{Comorbid Illness}

Comorbidity is defined as previously confirmed medical, psychiatric, or other problems, or relevant hospitalization.

\section{Medication Discontinuation}

This indicates when a patient stopped treatment, i.e, when patients with epilepsy who have been on antiepileptic treatment have stopped treatment due to any reason and came for follow-up again.

\section{Controlled Seizures}

In this study, controlled seizures were defined as no history of seizure attacks at least one year before data collection time.

\section{Data Analysis}

First, the collected data were checked for completeness and consistency and entered to Epi-Data version 3.1 software. Then, the data were exported to Statistical Package for Social Science (SPSS-version 20) for analysis. The original total score of the SRQ-20 questionnaire was converted into a binary variable based on its sum score. 
Binary logistic regression analysis was carried out to identify factors associated with psychological distress. Variables with $p$-values of less than 0.25 in the bivariable analysis were considered as candidates for the multivariable model to control possible confounders. Accordingly, sex of respondents, illness duration, monthly income, current substance use, level of social support, suicidal attempt, and seizure status in the last one year were tested as potential predictors and were entered together for multivariable analysis. Multi co-linearity of these variables was also checked using the variance inflation factors test (VIF) and co-linearity was not found in between the candidate variables as evidenced by VIF value $<10$ (the actual value of all variables was $\leq 1.4$ ). In the final model, variables with $p$-values of less than 0.05 were considered as having a statistically significant association with psychological distress. Odds ratio with $95 \%$ CI was used to measure the strength of the association.

\section{Ethics Approval and Consent to Participate}

This study was ethically approved by the Institutional Review Board (IRB) of Dilla University, College of Health and Medical Science in accordance with Helsinki declarations. A permission letter was also obtained from the Gedeo zone health department office. Written consent was taken from each participant prior to the interview after providing a brief explanation regarding the study. Each participant was also informed that they have the right to refuse or to withdraw their participation at any time they want and no harm will be imposed as a result of their participation or refusal. During data collection, personal identifiers like name and phone numbers of the study participants had never been recorded. The collected data were kept confidential and used only for the purpose of the study.

\section{Results}

\section{Socio-Demographic Characteristics of Study Participants}

A total of 321 anti-epileptic treatment attendees participated in the study with a full response rate $(100 \%)$. About $39.6 \%$ of participants were within the age category of $18-25$ years old with mean age (SD) age of 26.72 years (4.54). More than half (55.1\%) were married and had no formal education (Table 1).
Table I Socio-Demographic Characteristics of People with Epilepsy Attending Treatment in Gedeo Zone Public Health Hospitals, Southern Ethiopia $(n=321)$

\begin{tabular}{|c|c|c|c|}
\hline Variables & Categories & Frequency & Percentage \\
\hline \multirow[t]{3}{*}{ Age in years } & $18-25$ & 127 & 39.6 \\
\hline & $26-35$ & 117 & 36.4 \\
\hline & $>35$ & 77 & 24.0 \\
\hline \multirow[t]{2}{*}{ Sex } & Male & 148 & 46.1 \\
\hline & Female & 173 & 53.9 \\
\hline \multirow[t]{5}{*}{ Marital status } & Married & 177 & 55.1 \\
\hline & Single & 74 & 23.1 \\
\hline & Divorced/ & 29 & 9.0 \\
\hline & separated & & \\
\hline & Widowed & $4 I$ & 12.8 \\
\hline \multirow[t]{4}{*}{ Religion } & Protestant & 148 & 46.1 \\
\hline & Orthodox & 101 & 31.5 \\
\hline & Muslims & 46 & 14.3 \\
\hline & Catholic & 26 & 8.1 \\
\hline \multirow[t]{5}{*}{ Ethnicity } & Gedeo & 138 & 43.0 \\
\hline & Wolaita & 41 & 12.8 \\
\hline & Gurage & 46 & 14.3 \\
\hline & Oromo & 62 & 19.3 \\
\hline & Amhara & 34 & 10.6 \\
\hline \multirow[t]{6}{*}{ Occupation } & Governmental & 48 & 15.0 \\
\hline & Employee & & \\
\hline & Merchant & 76 & 23.7 \\
\hline & Farmers & 132 & $4 I .1$ \\
\hline & Daily laborers & 33 & 10.3 \\
\hline & Students & 32 & 10.0 \\
\hline \multirow[t]{4}{*}{ Educational level } & $\begin{array}{l}\text { No formal } \\
\text { education }\end{array}$ & 166 & 51.7 \\
\hline & Primary school & 75 & 23.4 \\
\hline & Secondary & 32 & 10.0 \\
\hline & $\begin{array}{l}\text { College and } \\
\text { above }\end{array}$ & 48 & 15.0 \\
\hline Average monthly & $<800$ ETB & 125 & 38.9 \\
\hline \multirow[t]{2}{*}{ income in ETB } & 800-2000 ETB & 113 & 35.2 \\
\hline & $>2000$ ETB & 83 & 25.9 \\
\hline
\end{tabular}

\section{Clinical and Psychosocial Factors}

Our finding showed that more than half $(51.1 \%)$ of patients attending anti-epileptic treatment had at least one episode of seizure within the last year. The majority of participants (86\%) were taking medication for generalized (tonic-clonic) seizures. More than one-third of the participants had a history of medication discontinuation at least once during their follow-up period without the recommendation of their 
physicians. Among all participants, 13.7 and $8.4 \%$ reported suicidal ideation and attempt, respectively (Table 2).

\section{Prevalence of Psychological Distress}

The prevalence of psychological distress among people with epilepsy attending the outpatient department was found to be $38.3 \%$ with a $95 \%$ confidence interval of (34.142.7\%) (Table 2). Among 297 individuals who screened positive for psychological distress symptoms, headache and feeling tense or nervous were the most common symptoms of psychological distress reported by 51.5 and $45.1 \%$ of respondents, respectively (Figure 1).

Table 2 Clinical and Psychosocial Factors of People with Epilepsy Attending Treatment in Gedeo Zone Public Hospitals, Southern Ethiopia $(n=321)$

\begin{tabular}{|c|c|c|c|}
\hline Variables & Categories & Frequency & Percentage \\
\hline \multirow[t]{3}{*}{ Social support } & Poor & 98 & 30.5 \\
\hline & Moderate & 95 & 29.6 \\
\hline & Strong & 128 & 39.9 \\
\hline \multirow[t]{2}{*}{ Seizure status } & Uncontrolled & 164 & 51.1 \\
\hline & Controlled & 157 & 48.9 \\
\hline \multirow[t]{2}{*}{ Types of seizure } & $\begin{array}{l}\text { Generalized tonic } \\
\text { clonic }\end{array}$ & 276 & 86 \\
\hline & Unclassified & 44 & 14 \\
\hline \multirow[t]{2}{*}{ Illness duration } & $>$ 5years & 149 & 46.4 \\
\hline & $\leq 5$ years & 172 & 53.6 \\
\hline \multirow{2}{*}{$\begin{array}{l}\text { Medication } \\
\text { discontinuation history }\end{array}$} & Yes & 87 & 27.1 \\
\hline & No & 234 & 72.9 \\
\hline \multirow[t]{4}{*}{ Types of medication } & $\begin{array}{l}\text { Phenobarbital } \\
\text { alone }\end{array}$ & 194 & 60.4 \\
\hline & $\begin{array}{l}\text { Phenobarbital \& } \\
\text { phenytoin }\end{array}$ & 19 & 5.9 \\
\hline & Sodium valproate & 41 & 12.8 \\
\hline & Carbamazepine & 67 & 20.9 \\
\hline \multirow[t]{2}{*}{ Comorbid conditions } & Present & 73 & 22.7 \\
\hline & Absent & 248 & 77.3 \\
\hline \multirow[t]{2}{*}{ Suicidal ideation } & Yes & 44 & 13.7 \\
\hline & No & 277 & 86.3 \\
\hline \multirow[t]{2}{*}{ Suicidal attempt } & Yes & 27 & 8.4 \\
\hline & No & 294 & 91.6 \\
\hline \multirow[t]{2}{*}{ Current substance use } & No & 235 & 73.2 \\
\hline & Yes & 86 & 26.8 \\
\hline \multirow{2}{*}{$\begin{array}{l}\text { High level of } \\
\text { psychological distress }\end{array}$} & Yes & 123 & 38.3 \\
\hline & No & 198 & 61.7 \\
\hline
\end{tabular}

\section{Correlates of Psychological Distress}

The multivariable logistic regression result showed that being female $[\mathrm{OR}=1.57$ (95\% CI: 1.01-4.80)], uncontrolled seizure $[\mathrm{OR}=1.96$ (95\% CI: 1.21-3.18)], and longer duration of illness $[\mathrm{OR}=3.16(95 \% \mathrm{CI}: 1.75-5.73)]$ were variables found to have a significant association with psychological distress (Table 3).

\section{Discussion}

Psychological distress is a frequent comorbid problem among physical and neurological conditions. ${ }^{23,27}$ It is more common among people with epilepsy. ${ }^{11}$ The presence of such comorbid psychological distresses can negatively affect the treatment outcome of people with epilepsy. Thus, assessment of its magnitude and associated factors is vital in developing countries like Ethiopia where epilepsy is the most prevalent neurological problem. ${ }^{7,28}$ The finding of this study showed that the prevalence of psychological distress was $38.3 \%$ with a $95 \%$ confidence interval of $34.1-42.7 \%$. The prevalence of psychological distress was relatively similar to the study done in Mexico $(36.4 \%)^{9}$ and the two studies conducted in the northwest part of Ethiopia among people with epileptic seizures $(35 \%) .{ }^{16,29}$ However, the finding showed that the prevalence of psychological distress was nearly threefold that of the WHO report regarding the global burden of psychological distress (14\%) among the general population. ${ }^{12}$ This indicates that the burden of psychological distress in patients with epilepsy in southern Ethiopia is higher than the general population. This might be a result of problems to cope with the status of epileptic seizures, pill burden, medication side effects, and community discrimination related to having an epileptic attack. Therefore, it is vital to address the psychosocial problems together with the biological treatment approach of epilepsy.

On the other hand, our finding showed a lower prevalence of psychological distress than a study done in India in which $50.5 \%$ of participants were screened positive for psychological distress among patients with epileptic seizures. ${ }^{30}$ The variation of screening tools might be a possible reason for such discrepant results, i.e, the study conducted in India used SRQ-24 which might increase the prevalence compared to the SRQ-20 that was used in our survey. In addition, there is a difference in sample size between our study and the study done in India $(n=101)$.

A Turkish study among prisoners with epilepsy also showed a higher prevalence of psychological distress as 


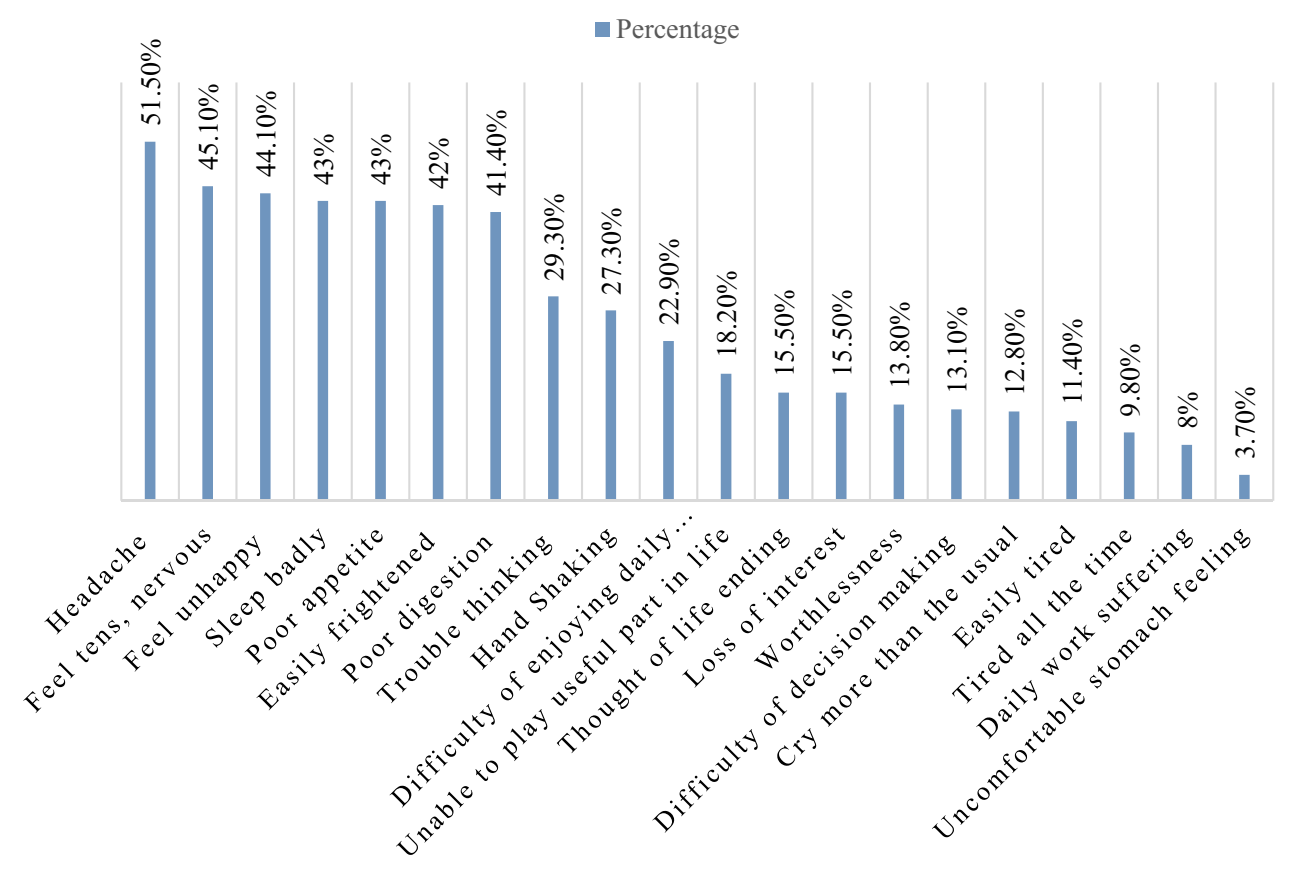

Figure I Symptoms of psychological distress among people with epilepsy in southern Ethiopia ( $\mathrm{n}=297)$.

compared to our results $(40.5 \%){ }^{31}$ The reason for this variation might be due to the fact that there may be stressors (comorbidities, poor social support, or economic problems) in prisons which can directly provoke psychological distress.

Regarding symptom presentation, "headache" was the first among primary complaints reported by more than half of the participants followed by "feeling nervous and unhappy." This is in agreement with a study conducted in northwest part of the country in which a large proportion of people with anti-epileptic treatment complained about headache. ${ }^{29}$ It can be possibly explained by the fact that headache is the most common associated symptom with seizure. But associated symptoms like headache are non-specific that could be due to other comorbidities or a side effect of medication. Thus, professionals are expected to pay due attention to address associated symptoms of psychological distress during clinical assessments of patients with epilepsy.

The other objective of our study was to identify associated factors of psychological distress. Accordingly, being female, uncontrolled seizures, and a longer duration of illness were significantly associated with psychological distress of people receiving anti-epileptic treatment in southern Ethiopia.

The odds of psychological distress among females were 1.5 times higher as compared to males. This confirms and supports the scientific evidence that common psychological distress like depression is more common among females than males. ${ }^{25,32}$ In developing countries, household activities such as cooking meals, feeding or nourishing children, and other responsibilities are usually left to women and may increase stress, which can exacerbate the existing psychological problems.

Participants whose seizure was not controlled in the past one year were more prone by twofold to have psychological distress as compared to their counterparts. This association might be explained by the fact that people with uncontrolled seizure attack commonly become hopeless and may lack trust in the drug therapies. ${ }^{33}$ This might be a reason for the higher occurrence of psychological distress. Finally, this study showed that participants with a longer duration of epilepsy onset (illness $>5$ years) were 3 times more vulnerable to psychological distress than individuals with $\leq 5$ years of illness duration. This might be explained by the situation when patients may face the fact that their illness has become chronic. They may develop a kind of additional physical or other comorbid condition and hopeless thoughts due to incurability of the illness and tiresome of medication intake. ${ }^{34}$

Generally, the findings of this study showed that there are unaddressed and highly prevalent psychological disturbances among people attending anti-epileptic outpatient treatment in southern Ethiopia. Thus, it is time for health 
Table 3 Bivariable and Multi Variable Logistic Analysis of Factors Associated with Psychological Distress Among People with Epilepsy Attending Treatment in Gedeo Zone Public Hospitals, Southern Ethiopia

\begin{tabular}{|c|c|c|c|c|c|}
\hline \multirow[t]{2}{*}{ Variables } & \multicolumn{2}{|c|}{ High Level Psychological Distress } & \multirow[t]{2}{*}{ COR (95\%C.I) } & \multirow[t]{2}{*}{ AOR (95\%C.I) } & \multirow[t]{2}{*}{ P-value } \\
\hline & Yes & No & & & \\
\hline \multicolumn{6}{|l|}{ Sex } \\
\hline Male & $47(31.8 \%)$ & $101(62.2 \%)$ & 1.00 & 1.00 & 1.00 \\
\hline Female & $76(43.9 \%)$ & $97(56.1 \%)$ & $1.68(1.06-2.66)$ & $1.57(1.01-4.80)$ & $0.007^{*}$ \\
\hline \multicolumn{6}{|c|}{ Monthly income } \\
\hline$<800$ & $55(44.0 \%)$ & $70(56.0 \%)$ & $1.28(0.76-2.15)$ & $0.6 I(0.32-1.16)$ & 0.133 \\
\hline $800-2000$ & $43(38.1 \%)$ & $70(61.9 \%)$ & $1.82(1.01-3.28)$ & $0.76(0.40-1.46)$ & 0.411 \\
\hline$>2000$ & $25(30.1 \%)$ & $58(68.9 \%)$ & 1.00 & 1.00 & 1.00 \\
\hline \multicolumn{6}{|l|}{ Seizure status } \\
\hline Uncontrolled & $76(46.3 \%)$ & $88(53.7 \%)$ & $2.02(1.27-3.19)$ & $1.96(1.21-3.18)$ & $0.006 *$ \\
\hline Controlled & $47(29.9 \%)$ & $110(70.1 \%)$ & 1.00 & 1.00 & 1.00 \\
\hline \multicolumn{6}{|l|}{ IIIness duration } \\
\hline$>5$ years & $48(32.2 \%)$ & $101(67.8 \%)$ & $1.63(1.03-2.57)$ & $3.16(1.75-5.73)$ & $0.001 *$ \\
\hline$\leq 5$ years & $75(43.6 \%)$ & $97(56.4 \%)$ & 1.00 & 1.00 & 1.00 \\
\hline \multicolumn{6}{|c|}{ Suicidal attempt } \\
\hline Yes & $14(5 \mid .9 \%)$ & $13(48.1 \%)$ & $0.54(0.24-1.20)$ & $0.56(0.23-1.33)$ & 0.190 \\
\hline No & $109(37.1 \%)$ & $185(62.9 \%)$ & 1.00 & 1.00 & 1.00 \\
\hline \multicolumn{6}{|l|}{ Substance use } \\
\hline No & $83(35.3 \%)$ & $152(64.7 \%)$ & 1.00 & 1.00 & 1.00 \\
\hline Yes & $40(46.5 \%)$ & $46(53.5 \%)$ & $0.62(0.38-1.03)$ & $0.69(0.40-1.19)$ & 0.186 \\
\hline \multicolumn{6}{|l|}{ Social support } \\
\hline Poor & $48(49.0 \%)$ & $50(51.0 \%)$ & $0.64(0.37-1.10)$ & $0.62(0.35-1.09)$ & 0.097 \\
\hline Moderate & $26(27.4 \%)$ & $69(72.6 \%)$ & $1.64(0.93-2.92)$ & $1.70(0.93-3.12)$ & 0.082 \\
\hline Strong & $49(38.3 \%)$ & $79(61.7 \%)$ & 1.00 & 1.00 & 1.00 \\
\hline
\end{tabular}

Note: $*$ Statistically significant variables. 1:00 = references.

professionals to incorporate the psycho-social support and psychotherapeutic approaches as complementary to the pharmacological intervention of epilepsy. This can also be used as a means to enhance the treatment compliance, therapeutic relationship, and overall treatment outcome of people with epilepsy with feasible and cost-effective services.

\section{Limitations of the Study}

Since the study is a cross-sectional study design, it may not provide clear relationships between the outcome variable and explanatory variables. Several of the symptoms reported, such as tiredness, headache, and stomach discomfort could be sideeffects of medications other than primary symptoms of psychological distress. In addition, our study addresses only individuals with epilepsy having outpatient follow-up and might not be representative of those who do not attend anti-epileptic treatment.

\section{Conclusions}

Our findings suggest health-care professionals should integrate psychological interventions and mental health screening strategies together with anti-epileptic care service as a means to improve the treatment outcome. Furthermore, public health surveillance systems should include questions on seizures, and mental health to better examine the associations among these disorders. More emphasis should be given to the management of women with epilepsy, people with uncontrolled seizures and individuals having a longer duration of illness.

\section{Acknowledgments}

We would like to thank Dilla University for the provision of ethical approval. Our appreciation extends to study participants for their voluntary participation in the interview. Finally, we would like to thank the Gedeo zone 
health department staff for their support and coordination in all stages of this research work.

\section{Author Contributions}

All authors contributed to data analysis, drafting or revising the article, gave final approval of the version to be published, and agree to be accountable for all aspects of the work.

\section{Disclosure}

The authors declare that they have no competing interests.

\section{References}

1. Falco-Walter JJ, Scheffer IE, Fisher RS. The new definition and classification of seizures and epilepsy. Epilepsy Res. 2018;139:73-79. doi:10.1016/j.eplepsyres.2017.11.015

2. Fisher RS, Acevedo C, Arzimanoglou A, et al. ILAE official report: a practical clinical definition of epilepsy. Epilepsia. 2014;55 (4):475-482. doi:10.1111/epi.12550

3. Radhakrishnan K. Challenges in the management of epilepsy in resource-poor countries. Nat Rev Neurol. 2009;5(6):323. doi:10.10 38/nrneurol.2009.53

4. Ngugi AK, Bottomley C, Kleinschmidt I, Sander JW, Newton CR. Estimation of the burden of active and life-time epilepsy: a metaanalytic approach. Epilepsia. 2010;51(5):883-890.

5. Leonardi M, Ustun TB. The global burden of epilepsy. Epilepsia. 2002;43:21-25. doi:10.1046/j.1528-1157.43.s.6.11.x

6. Meyer A-C, Dua T, Ma J, Saxena S, Birbeck G. Global disparities in the epilepsy treatment gap: a systematic review. Bull World Health Organ. 2010;88:260-266. doi:10.2471/BLT.09.064147

7. Organization WH. Epilepsy: A Public Health Imperative: Summary. World Health Organization; 2019.

8. Beghi E, Giussani G, Nichols E, et al. Global, regional, and national burden of epilepsy, 1990-2016: a systematic analysis for the global burden of disease study 2016. Lancet Neurol. 2019;18(4):357-375. doi:10.1016/S1474-4422(18)30454-X

9. Domínguez-Aguilera M, Muñiz-Landeros C. Prevalence of psychiatric disorders in patients with epilepsy in a tertiary level care hospital: detection through the MINI PLUS international structured interview. Medicina Universitaria. 2017;19(74):3-6. doi:10.1016/j.rmu.2016. 11.003

10. Marsh L, Rao V. Psychiatric complications in patients with epilepsy: a review. Epilepsy Res. 2002;49(1):11-33. doi:10.1016/S09201211(02)00008-6

11. Khalid A, Aslam N. Psychological distress among patients with epilepsy. Indian J Psychol Med. 2011;33(1):45. doi:10.4103/02537176.85394

12. World Health Organization. Global burden of mental disorders and the need for a comprehensive, coordinated response from health and social sectors at the country level: report by the Secretariat. Geneva: WHO; 2012. Available from: https://apps.who.int/iris/handle/10665/ 78898. Accessed September 4, 2020.

13. Belayneh Z, Mekuriaw B. A systematic review and meta-analysis of anti-epileptic medication non-adherence among people with epilepsy in Ethiopia. Archives of Public Health. 2020;78:1-14. doi:10.1186/ s13690-020-00405-2

14. Rodin EA. Psychiatric disorders associated with epilepsy. Psychiatric Clinics. 1978;1(1):101-115.

15. Nuhu F, Yusuf A, Lasisi M, Aremu S. Emotional distress among people with epilepsy in Kaduna, Northern Nigeria. Ann Tropical Med Public Health. 2013;6(1):42-46. doi:10.4103/1755-6783.115179
16. Tareke M, Birehanu M, Amare D, Abate A. Common mental illness among epilepsy patients in Bahir Dar city, Ethiopia: a cross-sectional study. PLoS One. 2020;15(1):e0227854. doi:10.1371/journal. pone. 0227854

17. Ethiopia C. Summary and statistical report of the 2007 population and housing census. Addis Ababa, Ethiopia Federal Democratic Republic Ethiopia Population Census Commission. 2008;1.

18. Beusenberg M, Orley JH, Organization WH. A User's Guide to the Self Reporting Questionnaire (SRQ. Geneva: World Health Organization; 1994.

19. Hanlon C, Medhin G, Alem A, et al. Detecting perinatal common mental disorders in Ethiopia: validation of the self-reporting questionnaire and edinburgh postnatal depression scale. $J$ Affect Disord. 2008;108(3):251-262. doi:10.1016/j.jad.2007.10.023

20. Deribew A, Tesfaye M, Hailmichael Y, et al. Common mental disorders in TB/HIV co-infected patients in Ethiopia. BMC Infect Dis. 2010;10(1):201. doi:10.1186/1471-2334-10-201

21. Mekuriaw B, Belayneh Z, Shemelise T, Hussen R. Alcohol use and associated factors among women attending antenatal care in Southern Ethiopia: a facility based cross sectional study. BMC Res Notes. 2019;12(1):690. doi:10.1186/s13104-019-4703-4

22. Mekuriaw B, Zegeye A, Molla A, Hussen R, Yimer S, Belayneh Z. Prevalence of common mental disorder and its association with khat chewing among ethiopian college students: a systematic review and meta-analysis. Psychiatry j. 2020;2020.

23. Belayneh Z, Mekuriaw B, Mehare T, Shumy S, Tsehay M. Magnitude and predictors of common mental disorder among people with HIV/ AIDS in Ethiopia: a systematic review and meta-analysis. BMC Public Health. 2020;20:1-11. doi:10.1186/s12889-019-7969-5

24. Abiola T, Udofia O, Zakari M. Psychometric properties of the 3-item oslo social support scale among clinical students of Bayero University Kano, Nigeria. Malaysian J Psychiatry. 2013;22(2):32-41.

25. Mekuriaw B, Belayneh Z, Yitayih Y. Magnitude of Khat use and associated factors among women attending antenatal care in Gedeo zone health centers, southern Ethiopia: a facility based cross sectional study. $B M C$ Public Health. 2020;20(1):110. doi:10.1186/s12889-019-8026-0

26. Belayneh Z, Alemu W, Mekuriaw B, Abebe Z. Bipolar spectrum disorders and associated factors among adults attending an antiretroviral therapy clinic in gedeo zone health centers, southern ethiopia. Neuropsychiatr Dis Treat. 2019;15:503. doi:10.2147/NDT.S187669

27. Dessie G, Mulugeta H, Leshargie CT, Wagnew F, Burrowes S. Depression among epileptic patients and its association with drug therapy in sub-Saharan Africa: A systematic review and meta-analysis. PLoS One. 2019;14:3. doi:10.1371/journal. pone. 0202613

28. Molla A, Birhanie Mekuriaw EH, Mareg M. Treatment-seeking behavior towards epilepsy among rural residents in ethiopia: a cross-sectional study. Neuropsychiatr Dis Treat. 2020;16:433. doi:10.2147/NDT.S240542

29. Wubie MB, Alebachew MN, Yigzaw AB. Common mental disorders and its determinants among epileptic patients at an outpatient epileptic clinic in Felegehiwot Referral Hospital, Bahirdar, Ethiopia: cross-sectional study. Int J Ment Health Syst. 2019;13(1):1-10. doi:10.1186/s13033-019-0333-4

30. Singh P, Pandey AK. Psychiatric morbidity in epilepsy. Int $J$ Res Med Sci. 2017;5(10):4267. doi:10.18203/2320-6012.ijrms20174187

31. Altınöz AE, Meriç OT, ŞT A, Eşsizoğlu A, Coşar B. Psychiatric disorders comorbid with epilepsy in a prison sample. Seizure. 2016;40:133-135. doi:10.1016/j.seizure.2016.06.016

32. Cutler JL. Kaplan and Sadock's synopsis of psychiatry, eleventh edition. Journal of Psychiatric Practice. 2016;22(1):68-69.

33. Niriayo YL, Mamo A, Kassa TD, et al. Treatment outcome and associated factors among patients with epilepsy. Sci Rep. 2018;8 (1):1-9. doi:10.1038/s41598-018-35906-2

34. Organization WH, Epilepsy G, Diseases P, et al. Atlas: Epilepsy Care in the World. World Health Organization; 2005. 


\section{Publish your work in this journal}

Neuropsychiatric Disease and Treatment is an international, peerreviewed journal of clinical therapeutics and pharmacology focusing on concise rapid reporting of clinical or pre-clinical studies on a range of neuropsychiatric and neurological disorders. This journal is indexed on PubMed Central, the 'PsycINFO' database and CAS, and is the official journal of The International Neuropsychiatric Association (INA). The manuscript management system is completely online and includes a very quick and fair peer-review system, which is all easy to use. Visit http://www.dovepress.com/testimonials.php to read real quotes from published authors.

Submit your manuscript here: https://www.dovepress.com/neuropsychiatric-disease-and-treatment-journal 